\title{
Artificial Neural Network Modeling to Predict the Non-Linearity in Reaction Conditions of Cholesterol Oxidase from Streptomyces olivaceus MTCC 6820
}

\author{
Shraddha Sahu, Shailendra Singh Shera, Rathindra Mohan Banik* \\ Bioprocess Technology Laboratory, School of Biochemical Engineering, Indian Institute of Technology (Banaras Hindu \\ University), Varanasi, India \\ Email: ssahu.rs.bce11@itbhu.ac.in, *rmbanik.bce@itbhu.ac.in
}

How to cite this paper: Sahu, S., Shera, S.S. and Banik, R.M. (2019) Artificial Neural Network Modeling to Predict the Non-Linearity in Reaction Conditions of Cholesterol Oxidase from Streptomyces olivaceus MTCC 6820. Journal of Biosciences and Medicines, 7, 14-24.

https://doi.org/10.4236/jbm.2019.74002

Received: February 15, 2019

Accepted: April 8, 2019

Published: April 11, 2019

Copyright $\odot 2019$ by author(s) and Scientific Research Publishing Inc. This work is licensed under the Creative Commons Attribution International License (CC BY 4.0).

http://creativecommons.org/licenses/by/4.0/

\begin{abstract}
Cholesterol oxidase (COX) is widely used enzyme for total cholesterol estimation in human serum and for the fabrication of electro-chemical biosensors. COX is also used for the bioconversion of cholesterol; for the production of precursors of steroidal drugs and hormones. Enzyme activity depends decisively on defined conditions with respect to $\mathrm{pH}$, temperature, ionic strength of the buffer, substrate concentration, enzyme concentration, reaction time. Standardization of these parameters is desirable to attain optimum activity of the enzyme. The present work aims to build a neural network model using five input parameters $(\mathrm{pH}$, cholesterol concentration, 4-aminoantipyrine concentration, crude COX volume and horseradish peroxidase) and one output i.e., $\mathrm{COX}$ activity $(\mathrm{U} / \mathrm{ml})$ as a response. A feed forward back propagation neural network with Levenberg-Marquardt training algorithm was used to train the network. The network performance was assessed in terms of regression $\left(R^{2}\right)$, Mean Squared Error (MSE) and Mean Absolute Percentage Error (MAPE). A network topology of 5-10-1 was found to be optimum. The MSE, MAPE and $R^{2}$ values of the neural model were $0.0075 \%, 0.12 \%$ and $0.9792 \%$ respectively. The maximum predicted activity of COX was 1.073 $\mathrm{U} / \mathrm{ml}$, which was close to the experimental value i.e., $1.1 \mathrm{U} / \mathrm{ml}$ at simulated optimum assay conditions. MSE and MAPE depicted the precision in the prediction efficiency of the developed ANN model. Higher $R^{2}$ value showed a good correlation between the experimental and ANN predicted values. This proved the robustness of the ANN model to predict similar type of system (COX from other Streptomyces sp.) within the limits of the trained data set. The COX activity was enhanced by 1.71 folds after optimization of the reaction conditions.
\end{abstract}




\section{Keywords}

Cholesterol Oxidase, Artificial Neural Network, Optimization, Streptomyces olivaceus, Prediction

\section{Introduction}

Cholesterol oxidase (COX) (EC 1.1.3.6) is a bacterial flavoenzyme that catalyzes the oxidation of cholesterol to 4-cholesten-3-one with the simultaneous reduction of molecular oxygen to hydrogen peroxide [1]. Owing to its enormous applications in the field of clinical pathology for the estimation of total serum cholesterol [2], determination of cholesterol concentrations in food samples for the quality control assay, and for the commercial production of precursors of the steroidal hormones from cholesterol and its derivatives [3]; COX has come up as a useful biotechnological tool in present times. An increasing need for specific estimation of this steroid in clinical samples has enhanced the importance and demand of COX in the pharmaceutical industry.

COXs have been isolated and purified from various micro-organisms including Actinomyces lavendulae [4], Streptomyces fradiae [5], Streptomyces sp. [6]. Streptomyces are potent producers of valuable antibiotics and are also non-pathogenic in nature. As per the available literature, Streptomyces is a promising culture for COX production to meet the above mentioned applications. Various methods have been reported for the estimation of COX activity including colorometric enzymatic method [2], UV method using 4-cholestenone as a standard [7], and fluorometric enzymatic method [8] [9]. Detection of cholesterol by enzymatic method involving COX coupled with $\mathrm{H}_{2} \mathrm{O}_{2}$ is though extremely simple, specific and highly sensitive. It indicates the relative concentration of cholesterol indirectly by the measurement of $\mathrm{H}_{2} \mathrm{O}_{2}$. Coupling of $\mathrm{H}_{2} \mathrm{O}_{2}$ with chromogen like 4-aminoantipyrine and o-dianisidine in the presence of peroxidase yields adduct that exhibits highly absorbing chromophore Quiononeimine allowing more sensitive measurement of cholesterol than any other method. This approach makes it an effective assay method.

The enzyme activity depends on manifold factors and a general understanding of the particular features of enzymes produced by any new microbial source is required. Enzyme activity depends decisively on defined conditions with respect to $\mathrm{pH}$, temperature, ionic strength of the buffer, substrate concentration, enzyme concentration, reaction time, etc. Standardization of these parameters is desirable to attain optimum activity of the enzyme [10]. Enzymes display their highest activity at their respective optimum conditions, and deviations from the optimum cause a reduction in the activity, depending on the degree of deviation. Optimization of reaction conditions for an enzyme provides direct information about the optimal values of the parameter under study and combined effects of various enzyme assay parameters for the en- 
hancement of activity [11]. In the past decade, the enzyme assay conditions for cellulase and inulinase have been optimized by classical method [12] and factorial design with surface response analysis [13] respectively. As reported by Singh and Banik, 2014, the reaction conditions for L-Glutaminase was optimized using RSM and ANN models (Singh and Banik, 2014) [11]. Parameters optimization for an enzyme assay is a complex process due to interactions of the factors on which they depend. This complexity can be minimized up to a certain extent with the advent of new tools and methodologies in mathematics and statistics. Therefore, a combination of mathematical and computational methods capable of predicting enzyme activity would be helpful to enhance the COX activity thus optimizing the factors affecting COX activity. ANN mimics the neural functioning of human brain and is a data-driven approach primarily based on input-output data [14]. ANN is a model-independent technique capable of predicting highly variable and non-linear bio-catalytic reaction like enzymatic assays with high accuracy.

In the present paper, we have worked for the optimization of assay conditions for the estimation of COX produced by a new species of Streptomyces i.e. Streptomyces olivaceus MTCC 6820 using ANN. In order to achieve enhanced COX activity $(\mathrm{U} / \mathrm{ml})$, the assay conditions for new microbial source needs to be standardized as the effective operating conditions for every new system are different. The incorporation of substrate concentration (cholesterol and 4-aminoantipyrine), $\mathrm{pH}$ of reaction mixture, enzyme concentrations (COX and peroxidase) as input parameters enable the development of robust ANN network for prediction of the response. To the best of our knowledge, this would be the first report on cholesterol oxidase activity by Streptomyces olivaceus MTCC 6820.

\section{Materials and Methods}

\subsection{Chemicals Used}

All the chemicals used were of analytical grade. Cholesterol was purchased from Sigma Aldrich Pvt. Ltd and Horseradish peroxidase was purchased from Sisco Research Laboratories, Mumbai, India.

\subsection{Microorganisms and Growth Media}

Streptomyces sp. including S. niger MTCC 4010, S. fradiae MTCC 4002, S. olivaceus MTCC 6820, S. hygroscopicus MTCC 4003, S. annulatus MTCC 6818, and S. clavifer MTCC 4150 were procured from Microbial Type Culture Collection, Institute of Microbial Technology, Chandigarh, India. All the Streptomyces cultures were maintained in the Streptomyces growth medium containing $(\mathrm{g} / \mathrm{L})$ : glucose -4 , yeast extract -4 , malt extract $-1, \mathrm{CaCO}_{3}-2$ and agar -12 ; $\mathrm{pH}$ was adjusted to 7.2 with $\mathrm{KOH}$. The slants were incubated at $30^{\circ} \mathrm{C} \pm 2^{\circ} \mathrm{C}$ for $48-72 \mathrm{~h}$ for the growth of organism, preserved at $4^{\circ} \mathrm{C}$ in the refrigerator. All the cultures were routinely sub-cultured in every 30 days. 


\subsection{Medium Components and Culture Conditions}

The production medium for COX contained $(\mathrm{g} / \mathrm{L})$ : cholesterol -2 , glucose-12, starch-9, yeast extract-6, peptone-4, $\left(\mathrm{NH}_{4}\right)_{2} \mathrm{SO}_{4}-7.5$, cholesterol-2, $\mathrm{K}_{2} \mathrm{HPO}_{4}-1, \mathrm{MgSO}_{4}-0.5, \mathrm{NaCl}-1, \mathrm{MnSO}_{4}-0.008, \mathrm{CaSO}_{4}-0.002, \mathrm{ZnSO}_{4}-0.002$, $\mathrm{FeSO}_{4}-0.02, \mathrm{CaCl}_{2}-0.0002$ and Tween $80-10 \mathrm{ml}$ [5]. COX production was carried out in $250 \mathrm{ml}$ Erlenmeyer flask, incubated at $30^{\circ} \mathrm{C} \pm 2{ }^{\circ} \mathrm{C}$ for $72 \mathrm{~h}$ in an orbital shaker (Orbitek, Scigenics Biotech Pvt. Ltd., Chennai, India) at $180 \mathrm{rev} / \mathrm{min}$.

\subsection{Cholesterol Oxidase Assay and Protein Estimation}

COX activity assay was done by modified method of Allain et al. [1] [2]. $50 \mu \mathrm{L}$ of 6 $\mathrm{g} / \mathrm{L}$ cholesterol (dissolved in dimethyl formamide containing 5\% (v/v) Triton $\mathrm{X}-100$ ) was added to $1 \mathrm{ml}$ of reaction mixture containing $1 \mathrm{mM} 4$-aminoantipyrine, $5 \mathrm{mM}$ phenol, $5 \mathrm{U} / \mathrm{ml}$ horseradish peroxidase and sodium phosphate buffer $(20$ $\mathrm{mM}, \mathrm{pH}$ 7.0); pre-incubated for $5 \mathrm{~min}$ at $30^{\circ} \mathrm{C} .100 \mu \mathrm{L}$ of crude enzyme extract was added to the pre-incubated reaction mixture to start the reaction and the incubation continued for $10 \mathrm{~min}$ at $30^{\circ} \mathrm{C}$. The reaction was terminated by placing the samples in a boiling water bath for $2 \mathrm{~min}$ and then immediately placed in an ice-bath for $2 \mathrm{~min}$ for color development. Absorbance was recorded at 500 nm (UV 1800 Spectrophotometer, Shimadzu, Japan). Blank was prepared by adding inactivated enzyme to the reaction mixture. One unit of cholesterol oxidase activity was defined as the amount of enzyme that converts $1 \mu \mathrm{mol}$ of cholesterol into 4-cholesten-3-one per minute at $30^{\circ} \mathrm{C}$.

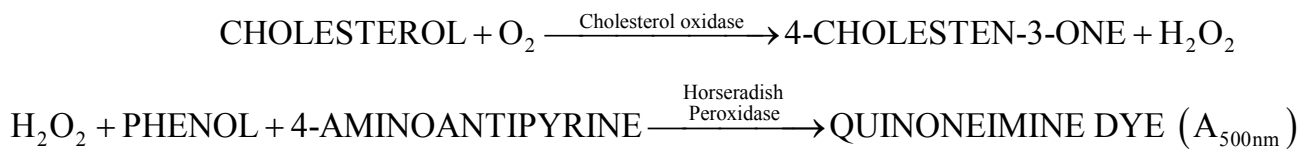

Protein concentration was determined by Bradford's method using Coommassie Brilliant Blue G-250 dye. The standard curve of bovine serum albumin (BSA) was prepared in the concentration range of 0.01 to $0.2 \mathrm{mg} / \mathrm{ml}$. Absorbance was recorded at $595 \mathrm{~nm}$ [15].

\subsection{Screening of COX Producing Microorganism}

Six different Streptomyces sp. as listed in Table 1 were procured from Microbial Type Culture Collection, Institute of Microbial Technology, Chandigarh, India.

Table 1. Estimation of cholesterol oxidase activity among different Streptomyces sp.

\begin{tabular}{cc}
\hline Streptomyces sp. & Cholesterol oxidase activity $(\mathrm{U} / \mathrm{ml})$ \\
\hline S. niger MTCC 4010 & 0.27 \\
S. fradiae MTCC 4002 & 0.32 \\
S. olivaceus MTCC 6820 & 0.625 \\
S. hygroscopicus MTCC 4003 & 0.472 \\
S. annulatus MTCC 6818 & 0.355 \\
S. clavifer MTCC 4150 & 0.254
\end{tabular}


All the six strains were examined for their extracellular COX producing ability under un-optimized enzyme assay conditions.

\subsection{Input Parameters and Design Matrix}

Enzyme activity is significantly influenced by substrate concentration, enzyme concentration, $\mathrm{pH}$, and incubation temperature. The enzyme assay parameters were optimized by classical method in our preliminary studies, out of which five most effective parameters were considered for ANN modeling. Five assay parameters viz. $\mathrm{pH}$ of the reaction mixture, cholesterol concentration, 4-aminoantipyrine concentration, crude COX volume and horseradish peroxidase were the determinants of COX activity assay and served as network inputs, whereas COX activity $(\mathrm{U} / \mathrm{ml})$ was the output. The range and levels of the independent factors studied are given in Table 2. The input range provided in the Minitab was based on the results of the preliminary studies; which resulted in a five-level-five factor CCD. The experimental design was obtained by applying central composite design (CCD) to five independent variables using Minitab version 17.0. The experimental design matrix consisting of the central values used for modeling are presented in Table 3.

\subsection{Artificial Neural Network Modeling}

The neural model was created in MATLAB 2017a (Mathworks, USA) using neural network toolbox (command nftool) with five input variables $\left(\mathrm{X}_{1}, \mathrm{X}_{2}, \mathrm{X}_{3}\right.$, $\mathrm{X}_{4}$ and $\mathrm{X}_{5}$ ) and one output variable (COX activity). A multilayer feed forward back propagation neural network was employed for the modeling and prediction of COX activity. The network architecture consisted of one input layer, one hidden layer and one output layer (shown in Figure 1). The network was trained using Levenberg-Marquardt learning algorithm till the preferred network accuracy was achieved by multiple trainings of the network concurrently adjusting the number of neurons in the hidden layer. The input and output dataset were divided into three sets: Training (22), Validation (5) and Testing (5). Network performance was monitored through performance plot and regression analysis at each step consisting of training, validation and testing.

Table 2. Independent variables used in the experimental design for ANN modeling along with their levels.

\begin{tabular}{ccccccc}
\hline \multirow{2}{*}{ Factors } & Name of factors & \multicolumn{5}{c}{ Levels } \\
\cline { 3 - 7 } & & $-\boldsymbol{\alpha}$ & $\mathbf{- 1}$ & $\mathbf{0}$ & $\mathbf{+ 1}$ & $\boldsymbol{+} \boldsymbol{\alpha}$ \\
\hline $\mathrm{X}_{1}$ & $\mathrm{pH}$ of the reaction mixture & 6 & 7 & 8 & 9 & 10 \\
$\mathrm{X}_{2}$ & Cholesterol concentration & 0.2 & 0.4 & 0.6 & 0.8 & 1.0 \\
$\mathrm{X}_{3}$ & 4-Aminoantipyrine & -0.5 & 0.5 & 1.0 & 1.5 & 2.5 \\
$\mathrm{X}_{4}$ & Crude COX volume & 0 & 50 & 100 & 150 & 200 \\
$\mathrm{X}_{5}$ & Horseradish Peroxidase & 0 & 5 & 10 & 15 & 20 \\
\hline
\end{tabular}


Table 3. CCD of five independent variables displaying experimental and ANN predicted COX activity.

\begin{tabular}{|c|c|c|c|c|c|c|c|}
\hline \multirow{2}{*}{ Run Order } & \multirow{2}{*}{$\mathrm{X}_{1}$} & \multirow{2}{*}{$\mathrm{X}_{2}$} & \multirow{2}{*}{$\mathrm{X}_{3}$} & \multirow{2}{*}{$\mathrm{X}_{4}$} & \multirow{2}{*}{$\mathrm{X}_{5}$} & \multicolumn{2}{|c|}{ COX Activity (U/ml) } \\
\hline & & & & & & Experimental & ANN Predicted \\
\hline 1 & 7 & 0.8 & 0.5 & 50 & 5 & 0.047 & 0.058 \\
\hline 2 & 8 & 0.6 & 1.5 & 100 & 20 & 0.803 & 0.796 \\
\hline 3 & 8 & 0.6 & 1.5 & 100 & 10 & 1.100 & 1.073 \\
\hline 4 & 9 & 0.4 & 2.5 & 150 & 5 & 0.580 & 0.596 \\
\hline 5 & 8 & 0.6 & 1.5 & 100 & 10 & 1.070 & 1.073 \\
\hline 6 & 8 & 0.6 & 1.5 & 200 & 10 & 0.671 & 0.664 \\
\hline 7 & 7 & 0.8 & 2.5 & 50 & 15 & 0.595 & 0.392 \\
\hline 8 & 8 & 0.6 & 1.5 & 100 & 10 & 1.080 & 1.073 \\
\hline 9 & 6 & 0.6 & 1.5 & 100 & 10 & 0.656 & 0.615 \\
\hline 10 & 7 & 0.4 & 0.5 & 50 & 15 & 0.545 & 0.471 \\
\hline 11 & 8 & 0.6 & 1.5 & 100 & 10 & 1.100 & 1.073 \\
\hline 12 & 9 & 0.4 & 0.5 & 50 & 5 & 0.005 & 0.007 \\
\hline 13 & 7 & 0.4 & 2.5 & 50 & 5 & 0.509 & 0.355 \\
\hline 14 & 9 & 0.4 & 2.5 & 50 & 15 & 0.504 & 0.500 \\
\hline 15 & 8 & 0.6 & 1.5 & 100 & 10 & 1.090 & 1.073 \\
\hline 16 & 8 & 0.6 & -0.5 & 100 & 10 & 0.322 & 0.413 \\
\hline 17 & 8 & 0.6 & 1.5 & 100 & 0 & 0.268 & 0.256 \\
\hline 18 & 8 & 1.0 & 1.5 & 100 & 10 & 0.919 & 0.891 \\
\hline 19 & 9 & 0.8 & 2.5 & 150 & 15 & 0.882 & 0.873 \\
\hline 20 & 7 & 0.8 & 2.5 & 150 & 5 & 0.705 & 0.769 \\
\hline 21 & 9 & 0.8 & 2.5 & 50 & 5 & 0.444 & 0.501 \\
\hline 22 & 7 & 0.4 & 2.5 & 150 & 15 & 0.532 & 0.764 \\
\hline 23 & 8 & 0.6 & 3.5 & 100 & 10 & 0.788 & 0.809 \\
\hline 24 & 8 & 0.6 & 1.5 & 0 & 10 & 0.105 & 0.097 \\
\hline 25 & 7 & 0.4 & 0.5 & 150 & 5 & 0.387 & 0.364 \\
\hline 26 & 8 & 0.2 & 1.5 & 100 & 10 & 0.667 & 0.643 \\
\hline 27 & 9 & 0.8 & 0.5 & 150 & 5 & 0.473 & 0.265 \\
\hline 28 & 9 & 0.4 & 0.5 & 150 & 15 & 0.657 & 0.730 \\
\hline 29 & 8 & 0.6 & 1.5 & 100 & 10 & 1.080 & 1.073 \\
\hline 30 & 7 & 0.8 & 0.5 & 150 & 15 & 0.809 & 0.757 \\
\hline 31 & 10 & 0.6 & 1.5 & 100 & 10 & 0.588 & 0.601 \\
\hline 32 & 9 & 0.8 & 0.5 & 50 & 15 & 0.455 & 0.247 \\
\hline
\end{tabular}

The performance of the ANN was determined in terms of regression coefficient $\left(R^{2}\right)$ and the prediction efficiency was evaluated statistically by Mean Absolute 


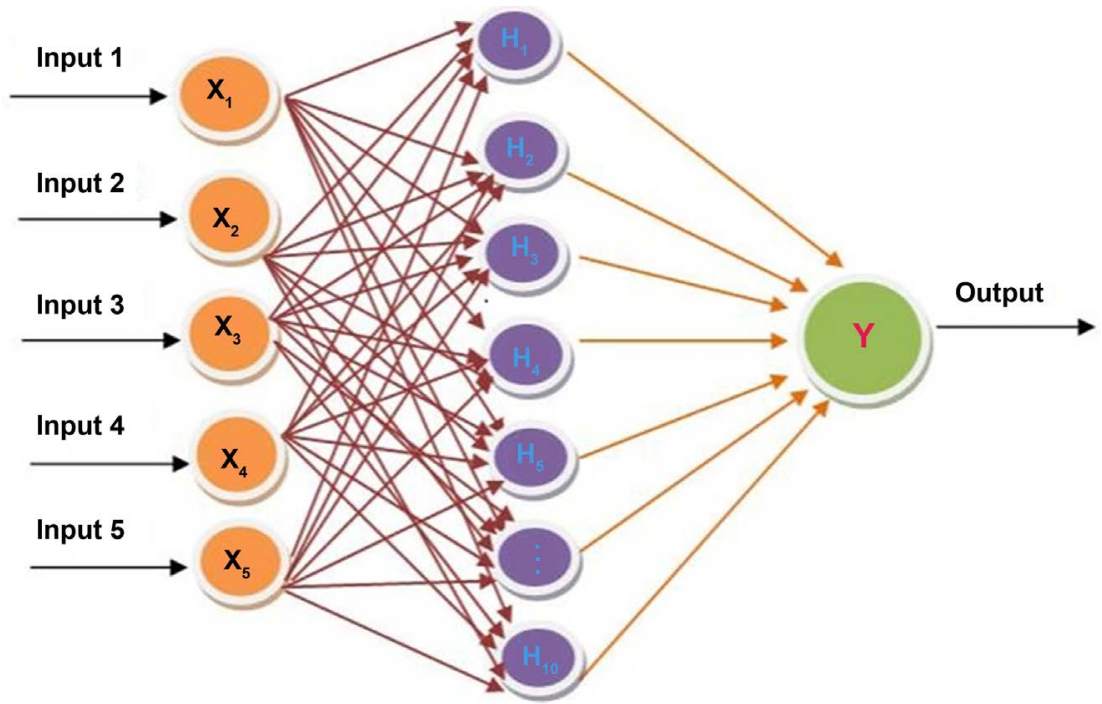

Figure 1. ANN architecture showing five input parameters at Input Layer $\left(\mathrm{X}_{1}, \mathrm{X}_{2}, \mathrm{X}_{3}, \mathrm{X}_{4}\right.$ and $\left.\mathrm{X}_{5}\right)$, neurons in the Hidden Layer $\left(\mathrm{H}_{1}, \mathrm{H}_{2}, \mathrm{H}_{3}, \mathrm{H}_{4}, \ldots, \mathrm{H}_{10}\right)$ and Output Layer (Y).

Percentage Error (MAPE) and Mean Squared Error (MSE). $R^{2}$, MAPE and MSE were calculated according to Equations (1)-(3) respectively [11] [14] [16].

$$
\begin{gathered}
R^{2}=1-\frac{\sum_{i=1}^{n}\left(y_{i}-y_{d i}\right)^{2}}{\sum_{i=1}^{n}\left(y_{d i}-y_{m}\right)^{2}} \\
\text { MAPE }=\frac{100}{n} \sum_{i=1}^{n}\left|y_{d i}-y_{i} / y_{d i}\right| \\
\text { MSE }=\frac{100}{n} \sum_{i=1}^{n}\left(\theta_{i}, p-\theta_{i}, e\right)^{2}
\end{gathered}
$$

where, $y_{d i}$ is the experimental value; $y_{i}$ is the predicted response; $y_{m}$ is the average of actual values and $\mathrm{n}$ is the number of experiments. $\theta_{i}, p$ is predicted value obtained from ANN model, $\theta_{i}$, e is experimental value.

\section{Results and Discussion}

COX from various microbial sources including Streptomyces sp., Nocardia sp., Pseudomonas sp., are commercially available but the COX obtained from Streptomyces has been found to be superior. Streptomyces being the producers of extracellular COXs are preferred for their potential in-vitro applications such as clinical pathology [2] [17], pharmaceutical and food industry [3] [18], biosensors [19] [20], etc. A number of Streptomyces sp. have been reported to produce extracellular COX, on the basis of which six Streptomyces strains were used in this study to get a potent strain with high COX yielding capacity, listed in Table 1. All of the six Streptomyces strains showed positive results for extracellular COX production. Amongst the six Streptomyces sp. used, Streptomyces olivaceus MTCC 6820 was found to produce significantly high level of COX under unoptimized assay conditions, therefore, it was further selected for the optimization study of COX enzyme assay conditions. 
ANN model was developed with $\mathrm{pH}$, cholesterol concentration, 4-aminoantipyrine, crude COX volume and horseradish peroxidase as five model inputs, Table 3. An experimental design matrix was prepared using CCD consisting of 32 experiments, as shown in Table 3. COX activity (U/ml) served as an output of the ANN, gives the quantitative prediction of the increase in enzyme activity when all the five independent variables are optimized. ANN captures the non-linear behavior of the input parameters thus, affecting the output of the system. The enzyme activity is largely affected by the physico-chemical parameters of the reaction conditions provided. The above mentioned reaction conditions needed to be optimized for a new source of COX from Streptomyces olivaceus to predict the optimum activity of COX. The optimum values of assay parameters were found to be: $\mathrm{pH}$ of the reaction mixture (8.0), cholesterol concentration $(0.6 \%(\mathrm{w} / \mathrm{v}))$, 4-aminoantipyrine $(1.5 \mathrm{mM})$, crude COX volume $(100 \mu \mathrm{l})$ and horseradish peroxidase $(10.0 \mathrm{U} / \mathrm{ml})$, which are different from those reported for cholesterol oxidase activity from other sources of cholesterol oxidase [21] [22]. Maximum cholesterol oxidase activity obtained was $1.1 \mathrm{U} / \mathrm{ml}$ (predicted-1.073 $\mathrm{U} / \mathrm{ml}$ ) at optimum levels of parameters, which was very close to the predicted response and is 1.71 times higher than the control. The optimized enzyme activity is the result of a combined effect of these assay parameters as a whole, which shows non-linearity. Hence, ANN modeling was the preferable method.

The hit and trial method was employed to determine the optimal number of neurons in the hidden layer to train the network. The network topology of 5-10-1 was found to be optimum and is presented in Figure 2. The ANN predicted values of the output (COX activity $\mathrm{U} / \mathrm{ml}$ ) for different range of 5 input parameters $(\mathrm{pH}$, cholesterol concentration, 4-aminoantipyrine concentration, crude COX volume and horseradish peroxidase concentration) were presented in Table 3. The performance of the neural network and prediction efficiency of ANN were measured in terms of regression coefficient $\left(R^{2}\right)$, MSE and MAPE, which were $0.9792 \%, 0.0075 \%$ and $0.12 \%$ respectively. The regression analysis of the training, validation and testing phase of the ANN is displayed in Figure 3. The obtained $R^{2}$ value is close to unity which confirms the excellent network performance and indicates that $97.92 \%$ variability of the data can be explained by the ANN model while only $2.08 \%$ of the total variation is not explained by the

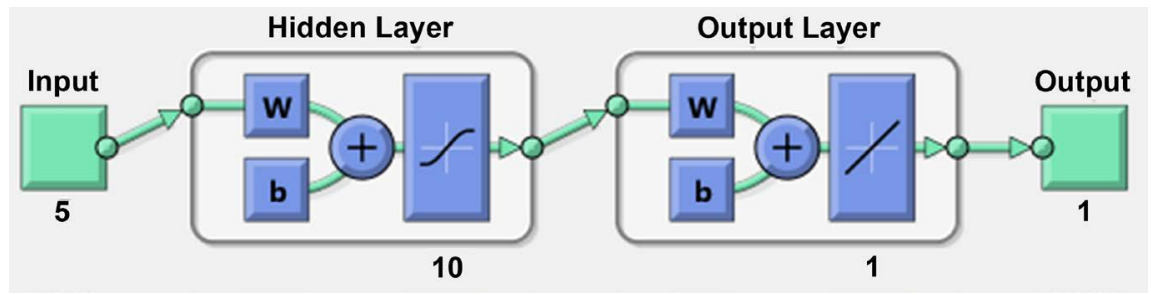

Figure 2. An optimized ANN topology with five input variables, 10 neurons at hidden layer with tansigmoid activation function and one output layer with Purelin transfer function. " $w$ " and " $b$ " in the hidden and output layer represents the weight and bias respectively; their values were adjusted automatically by the ANN function. 

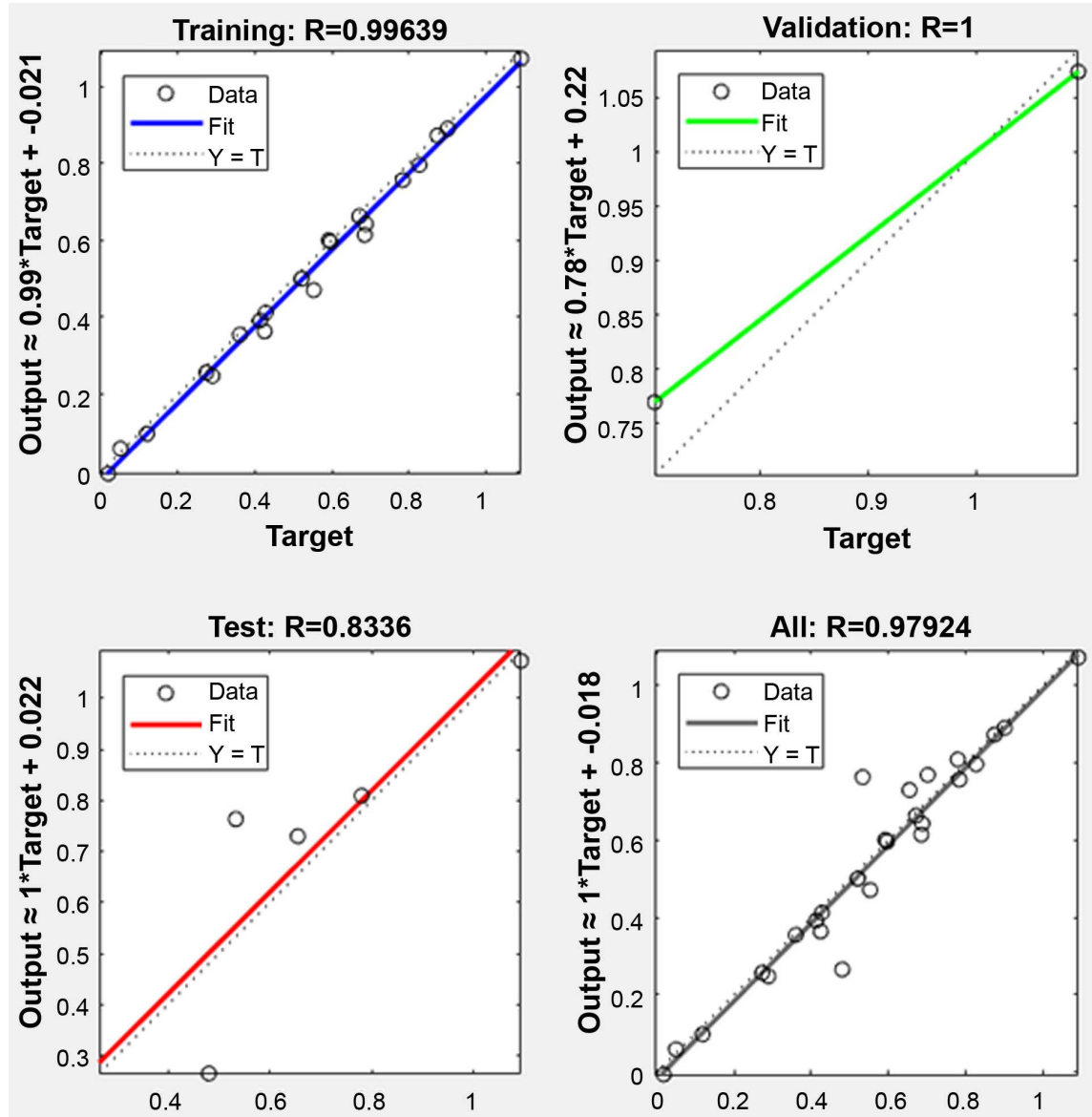

Figure 3. Regression analysis of ANN model generated by the ANN toolbox during training, validation and testing phase.

model [23]. The MSE and MAPE values determine the scale for prediction accuracy. MAPE $\leq 10 \%$ indicates high prediction efficiency, 10\% $\leq$ MAPE $\leq 20 \%$ depicts good prediction, $20 \% \leq$ MAPE $\leq 50 \%$ suggests reasonable prediction while MAPE $\geq 50 \%$ indicates inaccurate prediction [5]. The small MSE and MAPE values so obtained prove excellent prediction efficiency of the model. The values of $R^{2}$, MSE and MAPE altogether substantiated an efficient neural model for the prediction of responses.

\section{Conclusion}

The developed ANN model was successful in predicting the COX activity of Streptomyces olivaceus MTCC 6820. In addition, the excellent prediction accuracy of the ANN model illustrates its robustness in predicting the COX activity in similar type of systems within the range of dataset. ANN technique was based on the machine-learning approach, considering input-output data. This method was helpful in minimizing the labor, cost and enhancing the COX activity to a greater extent. The activity of COX was enhanced by 1.71 folds after optimization of reaction conditions viz. $\mathrm{pH}$ of reaction mixture (8.0), cholesterol concentration $(0.6 \% \mathrm{w} / \mathrm{v}), 4$-aminoantipyrine $(1.5 \mathrm{mM})$, crude COX volume $(100 \mu \mathrm{l})$ 
and horseradish peroxidase $(10.0 \mathrm{U} / \mathrm{ml})$. The generated ANN model will work as a template for the prediction, modeling and estimation of COX from other Streptomyces sp. or microorganisms using similar reaction conditions studied in this work.

\section{Acknowledgements}

Author acknowledges the School of Biochemical Engineering, Indian Institute of Technology (Banaras Hindu University), Varanasi, India for providing the support for infrastructure and research facility and Ministry of Human Resource and Development, Govt. of India for providing financial assistance in the form of Teaching Assistantship.

\section{Conflicts of Interest}

The authors declare no conflicts of interest regarding the publication of this paper.

\section{References}

[1] MacLachlan, J., Wotherspoon, A.T.L., Ansell, R.O. and Brooks, C.J.W. (2000) Cholesterol Oxidase: Sources, Physical Properties and Analytical Applications. Journal of Steroid Biochemistry and Molecular Biology, 72, 169-195.

https://doi.org/10.1016/S0960-0760(00)00044-3

[2] Allain, C.C., Poon, L.S., Chan, C.S.G., Richmond, W. and Fu, P.C. (1974) Enzymatic Determination of Total Serum Cholesterol. Clinical Chemistry, 20, 470-475.

[3] Mahato, S.B. and Garai, S. (1997) Advances in Microbial Steroid Transformation. Steroids, 62, 332-345. https://doi.org/10.1016/S0039-128X(96)00251-6

[4] Shirshova, G.A., Muntayen, L.N., Nazarova, T.S. and Nikitin, L.E. (1992) Comparative Study of Cholesterol Oxidase Biosynthesis of Two Strains of Streptomyces lavaendulae. Prikladnaia Biokhimiia i Mikrobiologiia, 28, 711-715.

[5] Tabatabei, Y.M., Zahraei, M., Aghaepour, K. and Kamranpour, N. (2001) Purification and Partial Characterization of Cholesterol Oxidase from Streptomyces fradiae. Enzyme and Microbial Technology, 28, 410-414. https://doi.org/10.1016/S0141-0229(00)00337-9

[6] Lolekha, P.H. and Jantaveesirirat, Y. (1992) Streptomyces a Superior Source of Cholesterol Oxidase in Serum Cholesterol Assay. Journal of Clinical Laboratory Analysis, 6, 405-409. https://doi.org/10.1002/jcla.1860060612

[7] Varma, R. and Nene, S. (2003) Biosynthesis of Cholesterol Oxidase by Streptomyces lavendulae NCIM 2421. Enzyme and Microbial Technology, 33, 286-291. https://doi.org/10.1016/S0141-0229(03)00126-1

[8] Huang, H.S., Kuan, J.C.W. and Guilbault, G.G. (1975) Fluorometric Enzymatic Determination of Total Cholesterol in Serum. Clinical Chemistry, 21, 1605-1608.

[9] Amundson, D.M. and Zhou, M. (1999) Fluorometric Method for the Enzymatic Determination of Cholesterol. Journal of Biochemical and Biophysical Methods, 38 43-52. https://doi.org/10.1016/S0165-022X(98)00036-0

[10] Bisswanger, H. (2014) Enzyme Assays. Perspectives in Science, 1, 41-55. https://doi.org/10.1016/j.pisc.2014.02.005

[11] Singh, P. and Banik, R.M. (2014) Optimization of Reaction Conditions of 
L-Glutaminase from Bacillus cereus MTCC 1305 Using RSM and ANN Model. International Journal of Basic and Applied Biology, 2, 57-64.

[12] Liang, Y., Feng, Z., Yesuf, J. and Blackburn, J.W. (2010) Optimization of Growth Medium and Enzyme Assay Conditions for Crude Cellulases Produced by a Novel Thermophillic and Cellulolytic Bacterium, Anoxybacillus sp. 527. Applied Biochemistry and Biotechnology, 160, 1841-1852. https://doi.org/10.1007/s12010-009-8677-x

[13] Burkert, J.F.M., Kalil, S.J., Filho, M.F. and Rodrigues, M.I. (2006) Parameters Optimization for Enzymatic Assays Using Experimental Design. Brazilian Journal of Chemical Engineering, 23, 163-170. https://doi.org/10.1590/S0104-66322006000200002

[14] Shera, S.S., Sahu, S. and Banik, R.M. (2018) Preparation of Drug Eluting Natural Composite Scaffold Using Response Surface Methodology and Artificial Neural Network Approach. Tissue Engineering and Regenerative Medicine, 15, 131-143. https://doi.org/10.1007/s13770-017-0100-Z

[15] Bradford, M.M. (1976) A Rapid and Sensitive Method for the Quantitation of Microgram Quantities of Protein Utilizing the Principle of Protein-Dye Binding. Analytical Biochemistry, 72, 248-254. https://doi.org/10.1016/0003-2697(76)90527-3

[16] Yadav, A.K., Malik, H. and Chandel, S.S. (2014) Selection of Most Relevant Input Parameters Using WEKA for Artificial Neural Network Based Solar Radiation Prediction Models. Renewable \& Sustainable Energy Reviews, 31,509-519. https://doi.org/10.1016/j.rser.2013.12.008

[17] Lolekha, P.H. and Jantaveesirirat, Y. (1992) Streptomyces. A Superior Source for Cholesterol Oxidase Used in Serum Cholesterol Assay. Journal of Clinical Laboratory Analysis, 6, 405-409. https://doi.org/10.1002/jcla.1860060612

[18] Ahmad, S. and Goswami, P. (2014) Application of Chitosan Beads Immobilized Rhodococcus sp. NCIM 2891 Cholesterol Oxidase for Cholestenone Production. Process Biochemistry, 49, 2149-2157. https://doi.org/10.1016/j.procbio.2014.10.004

[19] Aggarwal, V., Malik, J., Prashant, A., Jaiwal, P.K. and Pundir, C.S. (2016) Amperometric Determination of Serum Total Cholesterol with Nanoparticles of Cholesterol Esterase and Cholesterol Oxidase. Analytical Biochemistry, 500, 6-11.

https://doi.org/10.1016/j.ab.2016.01.019

[20] Gholivand, M.B. and Khodadadian, M. (2014) Amperometric Cholesterol Biosensor Based on the Direct Electrochemistry of Cholesterol Oxidase and Catalase on a Graphene/Ionic Liquid-Modified Glassy Carbon Electrode. Biosensors and Bioelectronics, 53, 472-478. https://doi.org/10.1016/j.bios.2013.09.074

[21] Yang, S. and Zhang, H. (2012) Optimization of Cholesterol Oxidase Production by Brevibacterium sp. Employing Response Surface Methodology. African Journal of Biotechnology, 33, 8316-8322.

[22] Lin, Y., Fu, J. and Song, X. (2010) Purification and Characterization of an Extracellular Cholesterol Oxidase from a Bordetella sp. Process Biochemistry, 45, 1563-1569. https://doi.org/10.1016/j.procbio.2010.06.005

[23] Bukzem, A.L., Signini, R., Santos, D.D.M., Lião, L.M. and Ascheri, D.P. (2016) Optimization of Carboxymethyl Chitosan Synthesis Using Response Surface Methodology and Desirability Function. International Journal of Biological Macromolecules, 85, 615-624. https://doi.org/10.1016/j.ijbiomac.2016.01.017 